\title{
The Impact of Human Immunodeficiency Virus Infection (HIV) on Lymphoma in South Africa
}

\author{
Moosa Patel ${ }^{1}$, Vinitha Philip ${ }^{1}$, Tanvier Omar², Dianne Turton ${ }^{3}$, Geoff Candy ${ }^{4}$, Atul Lakha1, \\ Sugeshnee Pather ${ }^{2}$ \\ ${ }^{1}$ Clinical Haematology Unit, Department of Medicine, Chris Hani Baragwanath Academic Hospital (CHBAH), \\ Johannesburg, South Africa \\ ${ }^{2}$ Department of Anatomical Pathology, National Health Laboratory Services (NHLS), Johannesburg, South Africa \\ ${ }^{3}$ Ampath Laboratories, Johannesburg (Previously, Department of Anatomical Pathology, NHLS), South Africa \\ ${ }^{4}$ Department of Surgery, University of the Witwatersrand, Johannesburg, South Africa, and Faculty of Health \\ Sciences, University of the Witwatersrand, Johannesburg, South Africa \\ Email: ${ }^{\text {moosa.patel@wits.ac.za }}$
}

Received 19 May 2015; accepted 26 June 2015; published 30 June 2015

Copyright (C) 2015 by authors and Scientific Research Publishing Inc.

This work is licensed under the Creative Commons Attribution International License (CC BY).

http://creativecommons.org/licenses/by/4.0/

c) (i) Open Access

\begin{abstract}
Human immunodeficiency virus (HIV) infection is endemic in South Africa. Non-Hodgkin lymphoma (NHL) occurs with increased frequency in HIV seropositive individuals. The increase in NHL has been more marked in the last decade, with HIV being the major contributor to this increase. More than $70 \%$ of the adult NHL patients at Chris Hani Baragwanath Academic Hospital (CHBAH), Soweto, Johannesburg, are HIV seropositive. In addition, HIV has impacted on the clinical presentation-being more aggressive and atypical. Histologically, HIV-NHL typically manifests as Bcell, high grade lymphomas, including diffuse large B-cell lymphoma (DLBCL); Burkitt lymphoma (BL); B-cell lymphoma, unclassifiable, with features intermediate between DLBCL and BL and plasmablastic lymphoma. The latter two entities, which were previously rare or unknown, have gained prominence in the last decade, occurring primarily in HIV seropositive individuals. HIVNHL, being associated with all these adverse prognostic factors results in a poorer overall survival.
\end{abstract}

\section{Keywords}

Human Immunodeficiency Virus (HIV), Non-Hodgkin Lymphoma (NHL), South Africa, High Grade, Adverse Prognostic Factors, Poorer Overall Survival

\footnotetext{
"Corresponding author.
}

How to cite this paper: Patel, M., Philip, V., Omar, T., Turton, D., Candy, G., Lakha, A. and Pather, S. (2015) The Impact of Human Immunodeficiency Virus Infection (HIV) on Lymphoma in South Africa. Journal of Cancer Therapy, 6, 527-535. 


\section{Introduction}

Human immunodeficiency virus (HIV) infection is endemic in South Africa. Based on a recent South African National HIV survey, it is estimated that in 2012, $12.2 \%$ of the population (6.4 million persons) were HIV positive [1]. The highest prevalence of HIV in the population is among females in the 30 - 34 year age group (36\%) and among males in the 35 - 39 year age group (28.8\%) [1]. Human immunodeficiency virus (HIV) and the resultant acquired immunodeficiency syndrome (AIDS) are associated with an increased risk of infection and malignancy, primarily as a consequence of immunodeficiency.

Lymphomas are malignancies of lymphoid cells, arising in lymph nodes and other lymphoid tissues, with Non-Hodgkin lymphoma (NHL) representing a heterogeneous group of indolent and aggressive disorders arising from B-cells, T-cells and natural killer cells (NK) [2]. High grade (aggressive), B-cell NHL is the classical haematological malignancy that complicates HIV [3]. However, in the last decade it has become apparent that Hodgkin lymphoma (HL) is an emerging HIV-associated malignancy [4] [5].

In sub-Saharan Africa, HIV is the major factor that has contributed to an increase in the incidence of lymphoma in this region. The impact of HIV on lymphoma (in particular, NHL) in South Africa, based on data from a large, tertiary level, public sector hospital will be presented.

\section{Lymphoma and HIV}

Lymphomas are encountered with increased frequency in people living with HIV/AIDS (PWHA) [3]. In the post HAART (highly active anti-retroviral therapy) era, non-Hodgkin lymphoma (NHL) is the most common malignancy in PWHA, superseding Kaposi's sarcoma. This is particularly true in resource-limited settings, such as sub-Saharan Africa, where there is a noticeable increase in NHL incidence [6]-[9]. HIV-NHL are typically highgrade, B-cell lymphomas, such as diffuse large B-cell lymphoma (DLBCL) and Burkitt lymphoma [3] [9] [10]. Indolent lymphomas tend to be more sporadic, and according to the AIDS Lymphoma Registry, account for $<3 \%$ of all NHL occurring in HIV seropositive patients [11].

The first report of the HIV/AIDS epidemic in Africa, was in 1984 [12]. The major risk factor for acquiring HIV in Africa occurs in relation to heterosexual relationships, and accounts for an approximately equal male to female ratio, as compared to developed countries (such as in Europe and North America), where the major risk groups include intravenous drug use and homosexual relationships, thus predominantly affecting males. Early in the HIV epidemic, there was no noticeable increase in the incidence of NHL in Africa, compared to the United States of America (USA) [12]. This was attributed to PWHA dying earlier in the course of their disease, largely from infectious complications such as tuberculosis and pneumonia. The early mortality prevented the subsequent or later development of NHL. In addition, there is underreporting of lymphoma in Africa, or the diagnosis may be missed, with a diagnosis of an infective cause of lymphadenopathy (such as tuberculosis) being favoured over lymphoma, especially in the absence of performing a formal diagnostic intervention, such as a fine needle aspirate or a lymph node biopsy [12]-[14].

Chris Hani Baragwanath Academic Hospital (CHBAH) is a large, tertiary, public sector, University of the Witwatersrand linked hospital, located in Soweto, Johannesburg. The first patient with HIV-NHL at CHBAH, was seen in 1993. In the decade that ensued, there was only a modest increase in HIV-NHL. This is corroborated by the study of Stein et al., 2008, in which it was shown that the percentage seropositivity of NHL in a South African cohort (which included patients from $\mathrm{CHBAH})$ was $44.4 \%$, with a relative risk of $5.9(95 \% \mathrm{CI}=5.3$ 8.1), during the period 1995-2004 [15]. This study, together with other studies published in the 1990's and early 2000's, suggested a consistently lower risk of NHL occurring in relation to HIV, compared to the Western world [16]. However, in the last decade, at our single institution, there has been a significant increase in both patient numbers and HIV seropositivity (see Figure 1 and Figure 2 and Table 1). Indeed, NHL is the commonest haematological malignancy seen in adults at CHBAH, accounting for an average of $40 \%$ of the total number of patients with haematological malignancies at our institution (see Figure 1). Thus, the focus of this review relates to the increased incidence of NHL in the setting of HIV, and the impact of this increase in our patient population.

\section{Non-Hodgkin Lymphoma and HIV}

\subsection{Epidemiology}

Sub-Saharan Africa is the epicentre of the HIV/AIDS pandemic, with South Africa being home to 6.4 million individuals living with HIV/AIDS. HIV significantly increases the risk of acquiring certain malignancies, with 


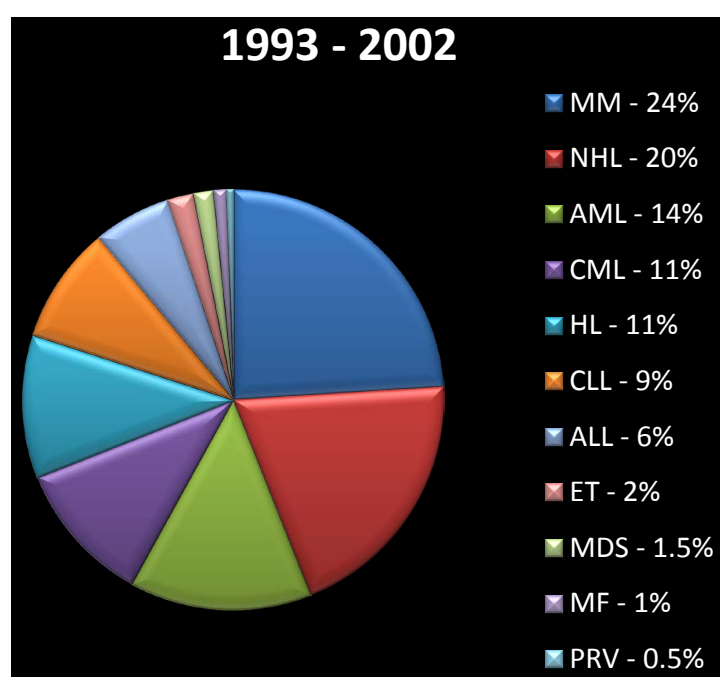

(a)

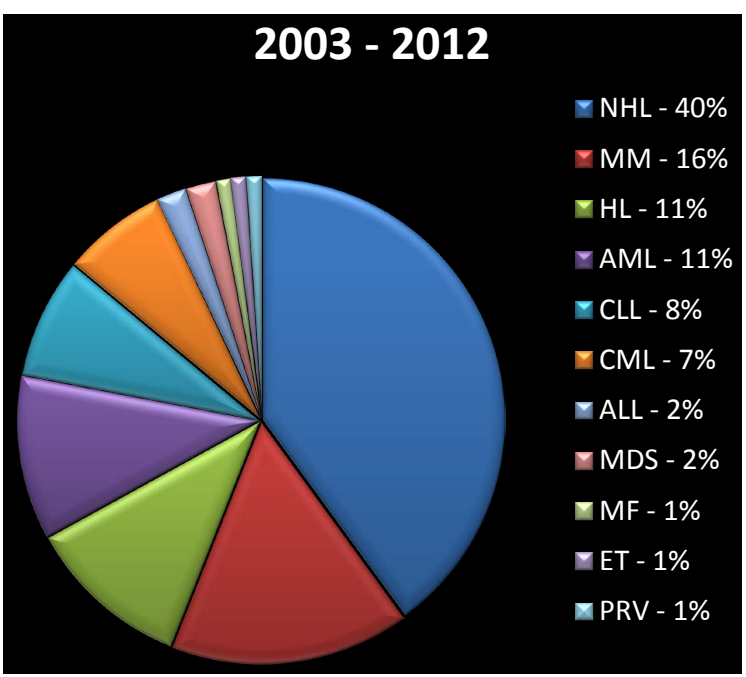

(b)

Figure 1. (a): 1993-2002 and (b): 2003-2012 showing the contribution of the different haematological malignancies as encountered during two time periods (decades), in the adult Clinical Haematology unit at CHBAH. $(\mathrm{MM}=$ multiple myeloma; NHL = non-Hodgkin lymphoma; $\mathrm{AML}$ = acute myeloid leukemia; $\mathrm{CML}$ = chronic myeloid leukemia; $\mathrm{HL}=$ Hodgkin lymphoma; CLL = chronic lymphocytic leukemia; ALL = acute lymphoblastic leukemia; ET = essential thrombocythemia; $\mathrm{MDS}=$ myelodysplastic syndrome; MF = myelofibrosis/primary myelofibrosis; $\mathrm{PRV}=$ polycythemia rubra vera).

Table 1. Non-Hodgkin Lymphoma at CHBAH, from 1993-2012, depicting the total number of patients, including the seronegative and seropositive patients as well as the percentage seropositivity (Adapted from Patel et al., 2013).

\begin{tabular}{|c|c|c|c|c|}
\hline Year & Number of patients & Seronegative & Seropositive & \% seropositivity \\
\hline 1993 & 20 & 19 & 1 & $5 \%$ \\
\hline 1994 & 20 & 18 & 2 & $10 \%$ \\
\hline 1995 & 18 & 15 & 3 & $16.7 \%$ \\
\hline 1996 & 28 & 25 & 3 & $10.7 \%$ \\
\hline 1997 & 18 & 14 & 4 & $22.2 \%$ \\
\hline 1998 & 34 & 18 & 16 & $47.1 \%$ \\
\hline 1999 & 22 & 16 & 8 & $36.4 \%$ \\
\hline 2000 & 30 & 16 & 14 & $46.7 \%$ \\
\hline 2001 & 24 & 4 & 20 & $83.3 \%$ \\
\hline 2002 & 40 & 15 & 25 & $62.5 \%$ \\
\hline 2003 & 44 & 17 & 27 & $61.4 \%$ \\
\hline 2004 & 58 & 23 & 35 & $60.3 \%$ \\
\hline 2005 & 54 & 15 & 39 & $72.2 \%$ \\
\hline 2006 & 74 & 18 & 56 & $75.6 \%$ \\
\hline 2007 & 72 & 19 & 53 & $73.6 \%$ \\
\hline 2008 & 76 & 10 & 66 & $86.8 \%$ \\
\hline 2009 & 79 & 19 & 60 & $75.9 \%$ \\
\hline 2010 & 101 & 24 & 77 & $76.2 \%$ \\
\hline 2011 & 92 & 18 & 74 & $80.4 \%$ \\
\hline 2012 & 103 & 22 & 81 & $78.6 \%$ \\
\hline
\end{tabular}




\section{NHL AT CHBAH 1993-2012}

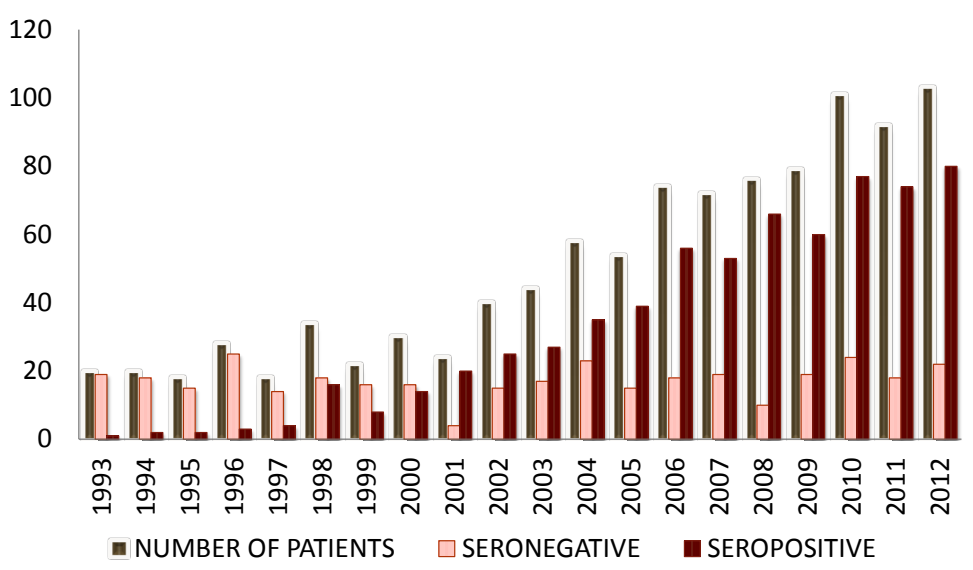

Figure 2. Bar graph showing the total number of patients with NHL, together with the seropositive and seronegative patients, from 1993-2012.

the risk of NHL being approximately 60 - 200 fold increased in seropositive individuals [17] [18].

At CHBAH, NHL is the most common haematological malignancy diagnosed in adults, currently, and during the period 2003 to 2012 (see Figure 1). During this period, NHL accounted for 40\% of the total number of patients with haematological malignancies and represents a significant increase from $24 \%$ a decade earlier. Earlier studies performed in the 1990's and early 2000's in South Africa (these studies included patients from CHBAH), showed only a modest increase in NHL in seropositive individuals, with odds ratios of 4.8, 5 and 5.9 respectively [15] [19] [20]. However, since 1998, there has been a noticeable increase in the proportion of seropositive patients with NHL (see Table 1), and furthermore, a significant increase in the total number of patients with NHL since 2002. For the period 2003 to 2012, the average percentage seropositivity increased from $34 \%$ to $74 \%$ and the average number of patients increased from 25 to 75 per year (see Table 1 and Figure 2). The number of seropositive patients with NHL continues to increase, with an average in excess of 100 patients per year in the last three years (2012 to 2014) (unpublished, personal data). Similar increases in the incidence of NHL in relation to the HIV pandemic have been noted in other parts of South Africa such as the Western Cape, as well as other parts of Africa, including Uganda [21] [22].

Table 2 shows a comparison of data on NHL patients in adults at CHBAH, during two time periods, viz., 1993 to 2005 (13 years) and 2006-2012 (7 years) [7] [23]. Data from these 2 studies further emphasize the impact of HIV on an increase in patient numbers, from an average of 32 patients per year in the first 13 year period to 85 patients per year in the latter 7 year period. The median age of all the patients was 43 and 42 years respectively, with a younger age of the HIV seropositive patients of 36 and 39 years respectively. Furthermore, the male to female ratio has changed, from there being a higher male to female ratio of 1.35:1 in the earlier study, to a slightly higher female predominance of 1.1:1 in the latter period (see Table 2).

In Europe and USA, lymphoma generally occurs in patients with long-standing or established HIV, who are on anti-retroviral therapy [24] [25]. This is different in South Africa, where HIV is a new or simultaneous diagnosis at the time of the diagnosis of lymphoma in $91 \%$ of the patients and $50 \%$ of the patients in the former and latter studies respectively (see Table 2). Moreover, despite their being a proportion of patients who were known to be HIV positive when the lymphoma was diagnosed, not all of these patients were on anti-retroviral therapy.

\subsection{Pathology}

The pathology of NHL has evolved in the last two decades at CHBAH, primarily based on the impact of HIV [7] [23]. This is depicted in Table 3.

Diffuse large B-cell lymphoma (DLBCL) is the commonest histological subtype of NHL in both seropositive and seronegative patients and has remained as such throughout these two time periods. In adults, BL at CHBAH is almost always of the immunodeficiency (HIV)—associated variety. Burkitt lymphoma (BL) and Burkitt-like lymphoma (BLL)—now called B-cell lymphoma, unclassifiable, with features intermediate between BL and 
Table 2. Comparison of data of NHL patients during two time periods at CHBAH (Adapted from Patel et al., 2007; Patel et al., 2013) [7] [23].

\begin{tabular}{ccc}
\hline & 1993-2005 (13 years) & 2006-2012 (7 years) \\
\hline Total number of patients & 410 & 597 \\
Number per year & 32 & 85 \\
M:F ratio & $1.35: 1$ & 42 \\
Median age in years & 43 & $78 \%$ \\
Percentage HIV seropositive & $46.5 \%$ & 39 \\
Median age of HIV seropositive patients & 36 & $50 \%$ new diagnosis \\
\hline
\end{tabular}

Table 3. Histological subtypes in NHL, during two time periods in HIV seropositive and HIV seronegative patients at CHBAH (Adapted from Patel et al, 2007; Patel et al., 2013) [7] [23].

\begin{tabular}{|c|c|c|c|c|c|}
\hline All patients 1993-2005 & $\begin{array}{l}\text { HIV positive } \\
\text { 1993-2005 }\end{array}$ & $\begin{array}{l}\text { HIV negative } \\
\text { 1993-2005 }\end{array}$ & $\begin{array}{l}\text { All patients } \\
\text { 2006-2007 }\end{array}$ & $\begin{array}{l}\text { HIV positive } \\
\text { 2006-2007 }\end{array}$ & $\begin{array}{l}\text { HIV negative } \\
\text { 2006-2012 }\end{array}$ \\
\hline DLBCL (39.2\%) & DLBCL (55\%) & DLBCL (23.6\%) & DLBCL (42.3\%) & DLBCL (43.5\%) & DLBCL (36.8\%) \\
\hline BL/BLL (8.9\%) & BL/BLL (18\%) & ALCL (11.2\%) & $\begin{array}{c}\text { BL/IM-BL, } \\
\text { DLBCL (21.9\%) }\end{array}$ & $\begin{array}{c}\text { BL/IM-BL, } \\
\text { DLBCL (25.9\%) }\end{array}$ & FL (11.7\%) \\
\hline $\begin{array}{l}\text { ALCL (8.7\%); SLL } \\
\text { (5.2\%); MCL (4.6\%); } \\
\text { PTCL, nos (4.6\%) }\end{array}$ & $\begin{array}{l}\text { ALCL (7\%); PEL } \\
(3.5 \%) ; \text { PBL (2.9\%) }\end{array}$ & $\begin{array}{l}\text { SLL (10.5\%); LL (8.8\%); } \\
\text { PTCL, nos (8.1\%) }\end{array}$ & PBL (19\%) & PBL (23\%) & ALCL (7.8\%) \\
\hline
\end{tabular}

DLBCL (IM-BL, DLBCL) has increased from 9\% to 22\%, while plasmablastic lymphoma (PBL) has increased from $3 \%$ to $23 \%$ in HIV positive patients. The histological subtypes that are noted in Table 3 are statistically significantly different ( $\mathrm{p}<0.05$ ) between HIV positive and HIV negative individuals for the time period 1993-2005, and 2006-2012 (with the exception of DLBCL). PBL, BL and IM-BL, DLBCL occur predominantly in seropositive individuals (>90\% - 95\% of the patients with these entities are seropositive, unpublished personal data), and are the histological subtypes now encountered more specifically in patients with HIV-NHL [26]-[29]. In contrast, the indolent lymphomas such as small lymphocytic lymphoma (SLL) and follicular lymphoma (FL) are seen predominantly in HIV negative individuals (see Table 3).

\subsection{Clinical Presentation and Outcome}

The clinical presentation and course of HIV-NHL patients tends to be more adverse and aggressive than in their seronegative counterparts. Table 4 shows a comparison of the clinical features of lymphoma patients over a 13 year period (1993-2005), at CHBAH. In general, lymphoma patients at CHBAH, irrespective of their HIV status, present late, with more adverse prognostic factors [30]. However, in addition to this, HIV-NHL, presents at a statistically significantly younger age, with more aggressive (high-grade) histology, more extranodal disease, and poorer prognosis (see Table 4 and Figure 3) [7]. Figure 3 shows the Kaplan-Meier survival curves in HIV seropositive and seronegative patients, with a statistically significantly inferior survival $(p<0.05)$ in HIV-NHL [7].

The management of HIV-NHL poses a formidable challenge because of the increased myelosuppression, increased frequency of opportunistic infections such as tuberculosis, the greater likelihood of organ dysfunction due to HIV, more frequent bone marrow involvement, potential drug-drug interactions of the anti-retrovirals with the chemotherapy, the more advanced and widespread nature of the disease at presentation and the predominance of aggressive histological subtypes. 


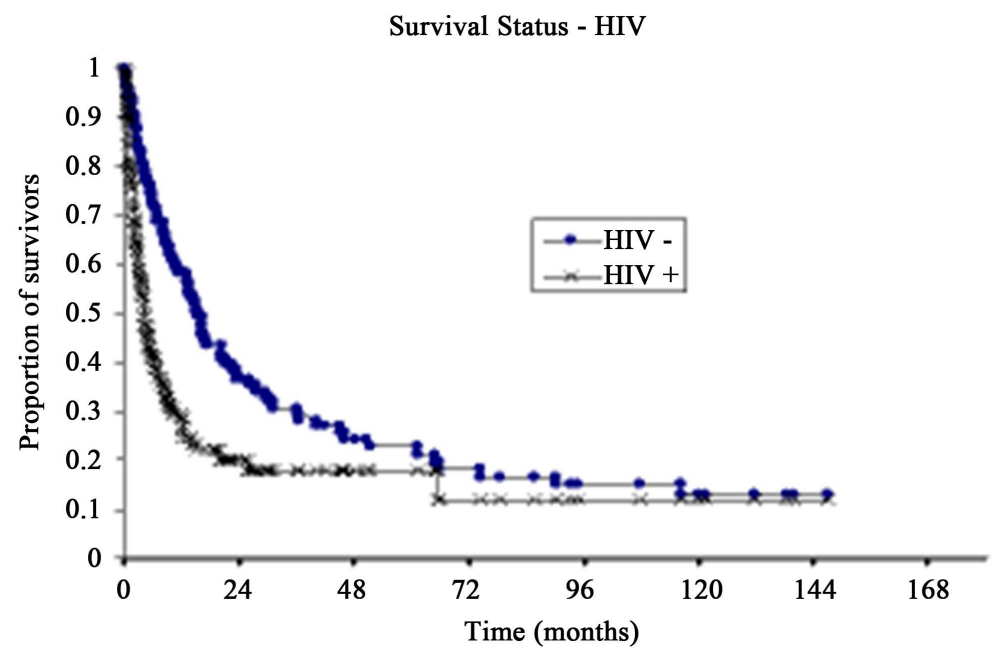

Figure 3. Kaplan Meier survival curve showing the impact of HIV on survival (Adapted from Patel et al., 2007) [7].

Table 4. Comparison of clinical features in NHL, in HIV seronegative and seropositive patients—1993 to 2005 (Adapted from Patel et al., 2007) [7].

\begin{tabular}{|c|c|c|c|}
\hline Variable & Seronegative & Seropositive & Statistical significance ( $\mathrm{p}$ value $<0.05$ ) \\
\hline Total number & 212 & 198 & \\
\hline Percentage & $53.5 \%$ & $46.5 \%$ & \\
\hline Median age & 48 years & 36 years & Yes \\
\hline $\mathrm{PS} \geq 2$ & $44 \%$ & $58 \%$ & \\
\hline “B” symptoms & $84 \%$ & $91 \%$ & \\
\hline Stage III/IV & $68 \%$ & $83 \%$ & \\
\hline High grade histology & $39 \%$ & $98 \%$ & Yes \\
\hline EN disease & $49 \%$ & $71 \%$ & Yes \\
\hline LDH increase & $85 \%$ & $93 \%$ & \\
\hline Increased B2-M & $62 \%$ & $83 \%$ & Yes \\
\hline Survival & 42 months & 11 months & Yes \\
\hline
\end{tabular}

PS = performance status; LDH = lactate dehydrogenase; EN = extranodal; B2-M = beta-2 microglobulin.

Treatment approaches include optimal supportive care (combination anti-retroviral therapy, anti-fungals, prophylactic antibiotics, growth factors such as G-CSF, blood and blood products), treatment of concurrent infections such as tuberculosis, together with standard combination chemotherapy, intra-thecal chemotherapy where indicated and radiotherapy where necessary. At CHBAH, standard therapy for HIV-DLBCL and HIV-PBL includes CHOP (cyclophosphamide, hydroxydaunorubicin, oncovin, prednisone) or CHOEP (CHOP plus etoposide) and more recently an ongoing, randomised study comparing CHOEP versus R-CHOEP (CHOEP plus rituximab), and an institutional based protocol of combination chemotherapy for BL (unpublished, personal data). However, in general, response rates in HIV-NHL are lower than in seronegative patients, despite the substantial progess made in the last decade in HIV lymphoma, using infusional regimens such as CDE/R-CDE, EPOCH/REPOCH and SCT where relevant [31]-[34].

An important feature in the management of HIV-NHL is the simultaneous or sequential use of combination anti-retroviral therapy (c-ART). Figure 4 shows the beneficial impact of simultaneous anti-retroviral therapy (this is our standard of practice) in our HIV-NHL patients. At the time of this review, only 29/198 patients with 
HIV positive patients - effect of ARVs

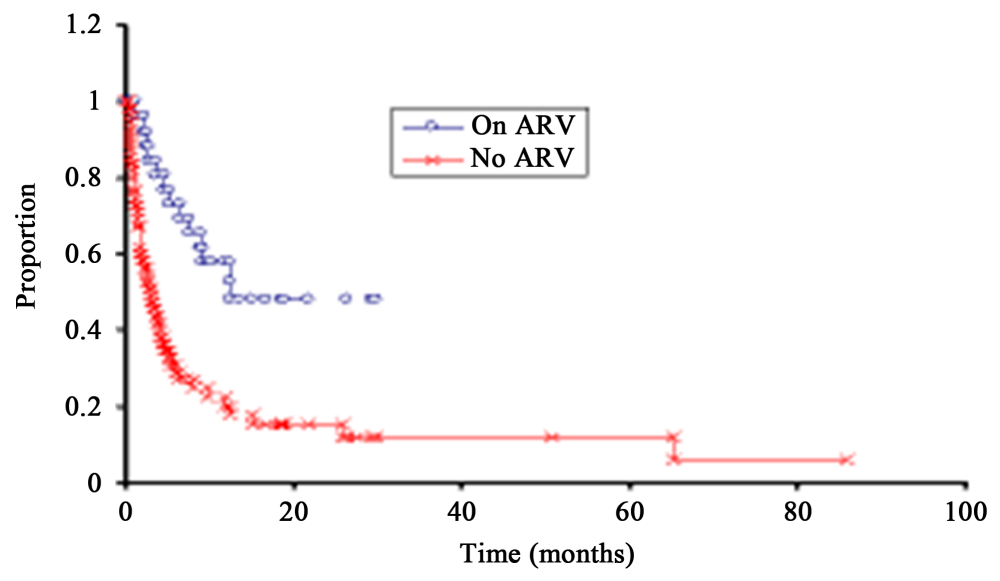

Figure 4. The impact of anti-retroviral therapy (ARV's) on survival (Adapted from Patel et al. 2007) [7].

HIV-NHL were on c-ART, as the "HIV-rollout" in South Africa began much later than in other areas of the world, in 2004 [7] [35]. The median CD4 count in this cohort of patients was 177ul/ml (range 8 - 1002) [7]. Combination anti-retroviral therapy (c-ART) is continued in patients who are already on treatment at the time of initiating the chemotherapy, and commenced as soon as possible in patients who are not on c-ART. These drugs are generally well tolerated from a myelosuppressive point of view (currently, the first line treatment does not include zidovudine and lamivudine). In addition, the NRTI's (nucleoside reverse transcriptase inhibitors) have no/minimal effects on drugs that are metabolised by the cytochrome p450 system in the liver, whereas NNRTI's (non-nucleoside reverse transcriptase inhibitors) induce the enzyme system, and the protease inhibitors inhibit drugs metabolised by the cytochrome p450 system. This may necessitate dose adjustments for appropriate drugdrug interactions [36].

\section{Conclusions}

Lymphoma is the commonest haematological malignancy encountered in adults at CHBAH. The increased incidence of NHL is directly related to the high seroprevalence of HIV in the population that CHBAH serves. NHL in the setting of HIV are typically high grade/aggressive B-cell lymphomas. Diffuse large B-cell (DLBCL); BL; B-cell NHL, with features intermediate between BL and DLBCL and PBL are the most frequent histological subtypes encountered. With the exception of DLBCL, all the above subtypes are very uncommon in HIV seronegative adults, with the latter two entities gaining prominence only in the last decade. In addition, HIV-NHL presents with other poor prognostic factors such as more frequent constitutional symptoms, more advanced stage disease, more bulk disease and more extranodal disease and overall, a shorter median survival. In addition to chemotherapy, cART forms the cornerstone of treatment and in our setting is administered concomitantly and simultaneously with chemotherapy. Atypical presentations are common and newer entities such as "double-hit" and "triple-hit" lymphomas, as well as "gray-zone" lymphomas are seen more frequently in the HIV seropositive population [37] [38].

The data presented in this review show that at CHBAH, NHL, over the past two decades is an evolving entity. There is little doubt that HIV has been and continues to be the major contributor to this evolution. It is thus essential that all attempts at preventing, controlling and lessening the burden and scourge of HIV continue and are escalated, in order to halt the increase in HIV-NHL prevalence and incidence, together with its deleterious clinical consequences, in South Africa.

\section{Acknowledgements}

Patients, medical and nursing staff of the Clinical Haematology unit, Department of Medicine, CHBAH; Infectious disease unit, Department of Medicine, CHBAH; Molecular Medicine and Haematology Department, CHBAH and NHLS; L Dzeng, J Johnstone, AB Rahmani, G Stander and J Webb. 


\section{References}

[1] Shisana, O., Rehle, T., Simbeyi, L.C., et al. (2012) South African National HIV Prevalence, Incidence and Behaviour Survey. HSRC Press, Cape Town, 2014.

[2] Foon, K.A., Ghobrial, I., Geskin, L.J., et al. (2006) The Non-Hodgkin Lymphomas. In: Lichtman, M.A., Beutler, E., Kipps, T.J., Seligsohn, U., Kaushansky, K. and Prchal, J.T., Eds., Williams Hematology, 7th Edition, McGraw Hill, New York, 1407-1459.

[3] Ziegler, J.L., Beckstead, J.A., Volberding, P.A., et al. (1984) Non-Hodgkin’s Lymphoma in 90 Homosexual Men: Relation to Generalised Lymphadenopathy and the Acquired Immunodeficiency Syndrome. The New England Journal of Medicine, 311, 565-570. http://dx.doi.org/10.1056/NEJM198408303110904

[4] Spina, M., Carbone, A., Gloghini, A., et al. (2011) Hodgkin's Disease in Patients with HIV Infection. Advances in Hematology, 2011, Article ID: 402682. http://dx.doi.org/10.1155/2011/402682

[5] Patel, M., Philip, V. and Fazel, F. (2011) Human Immunodeficiency Virus Infection and Hodgkin’s Lymphoma in South Africa-An Emerging Problem. Advances in Hematology, 2011, Article ID: 578163. http://dx.doi.org/10.1155/2011/578163

[6] Ulrickson, M., Press, O.W. and Casper, C. (2012) Epidemiology, Diagnosis, and Treatment of HIV-Associated NonHodgkin's Lymphoma in Resource Limited Settings. Advances in Hematology, 2012, Article ID: 932658. http://dx.doi.org/10.1155/2012/932658

[7] Patel, M., Philip, V., Turton D., et al. (2007) The Impact of HIV on Non-Hodgkin's Lymphoma at Chris Hani Baragwanath Hospital. Haematologica, 92, 273.

[8] Casper, C. (2011) The Increasing Burden of HIV-Associated Malignancies in Resource-Limited Regions. Annual Review of Medicine, 62, 157-170. http://dx.doi.org/10.1146/annurev-med-050409-103711

[9] Bernadi, D., Spina, M. and Tirelli, U. (2011) AIDS-Lymphoma. In: Cavalli, F., Armitage, J. and Longo, D., Eds., Annual of Lymphoid Malignancies, Martin Dunitz Ltd., London, 109-116.

[10] Goedert, J., Cote, T., Virgo, P., et al. (1998) Spectrum of AIDS-Associated Malignant Disorders. Lancet, 351, 18331839. http://dx.doi.org/10.1016/S0140-6736(97)09028-4

[11] Levine, A.M., Li, P., Cheung, T., Tulpule, A., Von Roenn, J., Nathwani, B.N. and Ratner, L. (2000) Chemotherapy Consisting of Doxorubicin, Bleomycin, Vinblastine and Dacarbazine with Granulocyte-Colony-Stimulating-Factor GCSF in HIV Infected Patients with Newly Diagnosed Hodgkin's Disease: A Prospective, Multi-Institutional AIDS Clinical Trials Group Study (ACTG 149). Journal of Acquired Immune Deficiency Syndromes, 24, 444-450. http://dx.doi.org/10.1097/00126334-200008150-00009

[12] Clumeck, N., Sonnet, J., Taelman, H., Mascart-Lemone, F., De Bruyere, M., Vandeperre, P., et al. (1984) Acquired Immunodeficiency Syndrome in African Patients. New England Journal of Medicine, 310, 492-497. http://dx.doi.org/10.1056/NEJM198402233100804

[13] Parkin, D.M., Wabinga, H., Nambooze, S. and Wabwire-Mangen, F. (1999) AIDS-Related Cancers in Africa: Maturation of the Epidemic in Uganda. AIDS, 13, 2563-2570. http://dx.doi.org/10.1097/00002030-199912240-00010

[14] Adeniji, K.A. and Anjorin, A.S. (2000) Peripheral Lymphadenopathy in Nigeria. African Journal of Medicine and Medical Sciences, 29, 233-237.

[15] Stein, L., Urban, M.I., O’Connell, D., Yu, X.Q., Beral, V., Newton, R., et al. (2008) The Spectrum of Human Immunodeficiency Virus Associated Cancers in a South African Black Population: Results from a Case-Control Study, 19952004. International Journal of Cancer, 122, 2260-2265. http://dx.doi.org/10.1002/ijc.23391

[16] Parkin, D.M., Ferlay, J., Hamdi-Cherif, M., et al. (2004) Cancer in Africa: Epidemiology and Prevention. International Agency for Research on Cancer, Lyon.

[17] Tulpule, A. and Levine, A. (1999) AIDS-Related Lymphoma. Blood Reviews, 13, 147-150. http://dx.doi.org/10.1054/blre.1999.0112

[18] Beral, V., Peterman, T., Berkelman, R. and Jaffe, H. (1991) AIDS-Associated Non-Hodgkin Lymphoma. The Lancet, 337, 805-809. http://dx.doi.org/10.1016/0140-6736(91)92513-2

[19] Sitas, F., Bezwoda, W.R., Levin, V., Ruff, P., Kew, M.C., Hale, M.J., et al. (1997) Association between Human Immunodeficiency Virus Type 1 Infection and Cancer in the Black Population of Johannesburg and Soweto, South Africa. British Journal of Cancer, 75, 1704-1707. http://dx.doi.org/10.1038/bjc.1997.290

[20] Sitas, F., Pacella-Norman, R., Carrara, H., Patel, M., Ruff, P., Sur, R., et al. (2000) The Spectrum of HIV-1 Related Cancers in South Africa. International Journal of Cancer, 88, 489-492. http://dx.doi.org/10.1002/1097-0215(20001101)88:3<489::AID-IJC25>3.0.CO;2-Q

[21] Abayomi, E.A., Somers, A., Grewel, R., Sissolak, G., Bassa, F., Maartens, D., et al. (2011) Impact of the HIV Epidemic and Anti-Retroviral Treatment Policy on Lymphoma Incidence and Subtypes Seen in the Western Cape of South 
Africa, 2002-2009: Preliminary Findings of the Tygerberg Lymphoma Study Group. Transfusion and Apheresis Science, 44, 161-166. http://dx.doi.org/10.1016/j.transci.2011.01.007

[22] Parkin, D.M., Nambooze, S., Wabwire-Mangen, E. and Wabinga, H.R. (2010) Changing Cancer Incidence in Kampala, Uganda, 1991-2006. International Journal of Cancer, 126, 1187-1195.

[23] Patel, M., Philip, V., Lakha, A., et al. (2013) Trends in Non-Hodgkin Lymphoma (NHL) over the Past Two Decades at Chris Hani Baragwanath Academic Hospital (CHBAH). Proceedings of the Haematology Oncology Symposium, Johannesburg, 24-26 October 2013.

[24] Kaplan, L.D., Abrams, D.I., Feigal, E., McGrath, M., Kahn, J., Neville, P., et al. (1989) AIDS-Associated Non-Hodgkin’s Lymphoma in San Francisco. Journal of the American Medical Association, 261, 719-724. http://dx.doi.org/10.1001/jama.1989.03420050069041

[25] Mounier, N., Spina, M., Gabarre, J., Raphael, M., Rizzardini, G., Golfier, J.B., et al. (2006) AIDS-Related Non-Hodgkin Lymphoma: Final Analysis of 485 Patients Treated with Risk-Adapted Intensive Chemotherapy. Blood, 107, 38323840. http://dx.doi.org/10.1182/blood-2005-09-3600

[26] Swerdlow, S.H., Campo, E., Harris, N.L., Jaffe, E.S., Pileri, S.A., Stein, H., et al. (2008) WHO Classification of Tumours of Haematopoietic and Lymphoid Tissues. 4th Edition, International Agency for Research on Cancer, Lyon.

[27] Wiggil, T.M., Mayne, E.S. and Willem, P. (2013) Challenges in Lymphoma Diagnosis in HIV Positive Patients in the South African Setting. Transfusion and Apheresis Science, 49, 157-162. http://dx.doi.org/10.1016/j.transci.2013.07.020

[28] Pather, S., Mohamed, Z., McLeod, H. and Pillay, K. (2013) Large Cell Lymphoma: Correlation of HIV Status and Prognosis with Differentiation Profiles Assessed by Immunophenotyping. Pathology \& Oncology Research, 19, 695705. http://dx.doi.org/10.1007/s12253-013-9632-2

[29] Chetty, R., Hlatswayo, N., Muc, R., Sabaratnam, R. and Gatter, K. (2003) Plasmablastic Lymphoma in HIV+ Positive Patients: An Expanding Spectrum. Histopathology, 42, 605-609. http://dx.doi.org/10.1046/j.1365-2559.2003.01636.x

[30] Patel, M. (1994) Haematology. In: Huddle, K. and Dubb, A., Eds., Baragwanath Hospital 50 Years-A Medical Miscellany, Ultra Litho, 173-190.

[31] Spina, M., Jaeger, U., Sparano, J.A., Talamini, R., Simonelli, C., Michieli, M., et al. (2005) Rituximab plus Infusional Cyclophosphamide, Doxorubicin and Etoposide in HIV-Associated Non-Hodgkin Lymphoma: Pooled Results from 3 Phase 2 Trials. Blood, 105, 1891-1897. http://dx.doi.org/10.1182/blood-2004-08-3300

[32] Sparano, J.A., Lee, J.Y., Kaplan, L.D., Levine, A.M., Ramos, J.C., Ambinder, R.F., et al. (2010) Rituximab plus Concurrent Infusional EPOCH Chemotherapy Is Highly Active in HIV-Associated B-Cell Non-Hodgkin Lymphoma. Blood, 115, 3008-3016.

[33] Dunleavy, K., Little, R.F., Pittaluga, S., Grant, N., Wayne, A.S., Carrasquillo, J.A., et al. (2010) The Role of Tumor Histogenesis, FDG-PET, and Short Course EPOCH with Dose Dense Rituximab (SC-EPOCH-RR) in HIV-Associated Diffuse Large B-Cell Lymphoma. Blood, 115, 3017-3024. http://dx.doi.org/10.1182/blood-2009-11-253039

[34] Krishnan, A., Molina, A., Zaia, J., Smith, D., Vasquez, D., Kogut, N., et al. (2005) Durable Remission with Autologous Stem Cell Transplantation for High-Risk HIV-Associated Lymphomas. Blood, 105, 874-878. http://dx.doi.org/10.1182/blood-2004-04-1532

[35] Herbst, A.J., Cooke, G.S., Barnighausen, T., KanyKany, A., Tanser, F. and Newell, M.-L. (2009) Adult Mortality and Anti-Retroviral Treatment Rollout in Rural KwaZulu-Natal, South Africa. Bulletin of the World Health Organization, 87, 754-762. http://dx.doi.org/10.2471/BLT.08.058982

[36] Deeken, J.F., Pantonowitz, L. and Dezube, B.J. (2009) Targeted Therapies to Treat Non-AIDS-Defining Cancers in Patients with HIV on HAART Therapy: Treatment Considerations and Research Outlook. Current Opinion in Oncology, 21, 445-454. http://dx.doi.org/10.1097/CCO.0b013e32832f3e04

[37] Kluin, P.M., Harris, N.L., Stein, H., et al. (2008) B-Cell Lymphoma, Unclassifiable, with Features Intermediate between Diffuse Large B-Cell Lymphoma and Burkitt Lymphoma. In: Swerdlow, S.H., Campo, E., Harris, N.L., et al., Eds., WHO Classification of Tumours of Haematopoietic and Lymphoid Tissues, 4th Edition, International Agency for Research on Cancer, Lyon, 265-266.

[38] Jaffe, E., Stein, H., Swerdlow, S.H., et al. (2008) B-Cell Lymphoma, Unclassifiable, with Features Intermediate between Diffuse Large B-Cell Lymphoma and Classical Hodgkin Lymphoma. In: Swerdlow, S.H., Campo, E., Harris, N.L., et al., Eds., WHO Classification of Tumours of Haematopoietic and Lymphoid Tissues, 4th Edition, International Agency for Research on Cancer, Lyon, 267-268. 